\section{Effects of hormone therapy on the \\ endometrium in postmenopausal women: a one year randomized trial of low dose oral estradiol in association with a levonorgestrel-releasing intrauterine system or drospirenone}

\section{Efeitos da terapia hormonal no endométrio de mulheres na pós-menopausa: estudo clínico randomizado por um ano com estradiol oral em baixa dosagem em associação com sistema intrauterino com levonorgestrel ou drospirona}

Luiza Schvartzman 1

José Antônio Magalhães 2

Fernando Monteiro de Freitas 3

Carolina Pereira 4

Julia Azevedo 5

Edison Capp 6

Maria Celeste Osório Wender 7

\section{Abstract}

Objectives: to compare the endometrial effects and uterine bleeding patterns associated with treatment using (1) levonorgestrel-releasing intrauterine system (LNG-IUS) and estradiol (1 mg/day, p.o.) or (2) orally administered drospirenone $(2 \mathrm{mg} /$ day) and estradiol (1 mg/day).

Methods: thirty-four patients (aged $52.53 \pm 4.44$ in the LNG-IUS group and $53.15 \pm 4.018$ in the DRSP group) were randomized. The severity of menopausal symptoms was evaluated using the Kupperman index every three months. Transvaginal ultrasound, hysteroscopy and histological evaluation were repeated after 12 months. During this period, patients kept menstrual calendars. All categorical variables were described as percentages. Variables were tested for normal distribution and Student's $t$ test was applied for independent samples and ANOVA for repeated measures when appropriate. Data were considered to be significant when $p<0.05$.

Results: slight vaginal bleeding was reported in the first month of treatment by $53.3 \%$ of patients from the LNG-IUS/estradiol group compared with 7.7\% of patients from the drospirenone/estradiol group. There were no differences in endometrial thickness between the two groups throughout the study period. End-ofstudy histological findings showed atrophic endometrium in $53.3 \%$ of patients in the $L N G$ IUS/estradiol group compared with $76.9 \%$ of patients in the drospirenone/estradiol group.

Conclusions: our results suggest good endometrial protection with both HT regimens.

Key words Hormone, Postmenopause, Endometrium, Drospirenone, Levonorgestrel

\begin{abstract}
Programa de Pós-Graduação em Medicina: Ciências Médicas. Universidade Federal do Rio Grande do Sul. Porto Alegre, RS, Brasil. 2,3,6,7 Departamento de Ginecologia e Obstetrícia. Faculdade de Medicina. Universidade Federal do Rio Grande do Sul. Rua Dr. Barros Cassal, 411/22. Porto Alegre, RS, Brasil. CEP: 90.035-030.

E-mail: edcapp@ufrgs.br

4,5 Serviço de Ginecologia e Obstetrícia. Hospital de Clínicas de Porto Alegre. Porto Alegre, RS, Brasil.
\end{abstract}

\section{Resumo}

Objetivos: comparar os efeitos endometriais e no padrão de sangramento uterino de tratamento com (1) sistema intrauterine com levonorgestrel (SIULNG) e estradiol (1 mg/dia, v.o.) ou (2) associação oral de drospirenona (DRSP) (2 $\mathrm{mg} /$ dia) e estradiol (1 $\mathrm{mg} /$ dia).

Métodos: trinta e quatro pacientes (idade 52,53 \pm 4,44 grupo SIU-LNG e 53,15 4,018 grupo DRSP) foram randomizadas. A gravidade dos sintomas menopausais foi avaliado pelo indice de Kupperman a cada três meses. Ultrassom transvaginal, histeroscopia e avaliação histológica foram repetidos após 12 meses. Durante este periodo, as pacientes fizeram registros em calendários menstruais. Todas as variáveis categóricas foram descritas como porcentagens. Variáveis foram testadas para distribuição normal e teste $t$ de Student para amostras independents e ANOVA para medidas repetidas foram utilizados quando apropriado. Significância estatística foi considerada para $p<0.05$.

Resultados: leve sangramento vaginal foi relatado no primeiro mês de tratamento por 53,3\% das pacientes do grupo SIU-LNG/estradiol vs. 7,7\% das pacientes do grupo drospirenona/estradiol. Não houve diferença na espessura endometrial entre os grupos durante o periodo do estudo. Os achados histológicos ao final do estudo motraram endométrio atrófico em 53,3\% das pacientes no grupo SIU-LNG lestradiol vs. $76,9 \%$ das pacientes no grupo drospirenona/estradiol.

Conclusões: nossos resultados sugerem boa proteção endometrial com ambos os tratamentos de terapia hormonal.

Palavras-chave Hormônio, Pós-menopausa, Endométrio, Drospirenona, Levanogestrel 


\section{Introduction}

Hormone therapy (HT) is an effective way of improving menopause-related symptoms ${ }^{1-3}$ and reducing the risk of osteoporosis-related fractures in postmenopausal women. ${ }^{4}$ Two studies, however, have changed the views of physicians and patients concerning the benefits of HT: the Women's Health Initiative (WHI) trials ${ }^{5-7}$ and the Million Women Study (MWS). ${ }^{8}$ Since the publication of these studies, the recommendation of HT, as well as the risks and benefits associated with this therapy, have been constantly revised and re-assessed.1,2,4,9-11 Nevertheless, the North American Menopause Society 2 and the European Menopause and Andropause Society 10 recommend starting HT as early as possible in symptomatic peri- and postmenopausal women.

Combined estrogen-progestogen therapy is recommended for women with an intact uterus to avoid endometrial hyperplasia or neoplasia.12,13 According to WHI data, 14 unopposed estrogen therapy (in patients with a hysterectomy before inclusion in the study) was not related to increased risk of breast cancer (RR 0.77; CI 0.59-1.01) after six to eight years of follow-up. This led to the hypothesis that the slight increase in the risk of breast cancer in that population resulted from the combination of progestogen (medroxyprogesterone acetate) with estrogen. In addition, the sequential estrogen-progestogen regimen causes monthly bleeding in almost all postmenopausal women. The use of continuous combined therapy has been shown to reduce endometrial bleeding, with first-cycle amenorrhea rates of 40 to $70 \%$, decreasing with continued use. 12

One way of avoiding the limitations of combined estrogen-progestogen treatment is the use of lowdose estrogen, which provides symptomatic relief and maintenance of bone mineral density. ${ }^{4}$ Low dose therapy also has the least side-effects 2,15 and the lowest risk of venous thromboembolism when compared to usual dosages. 16

The levonorgestrel-releasing intrauterine system (LNG-IUS) was initially developed as a contraception method. It releases $20 \mu \mathrm{g} /$ day of levonorgestrel, with low systemic absorption, when compared to oral administration. ${ }^{17}$ There are few prospective studies evaluating LNG-IUS use in HT, always associated with conventional estrogen doses. ${ }^{18-20}$

Drospirenone (DRSP) is a synthetic, spironolactone-derived progestogen with a pharmacological profile that closely mimics that of endogenous progesterone.21-23 Several studies have demonstrated the safety and efficacy of continuous combined oral HT with $1 \mathrm{mg} 17 \beta$-estradiol (E2) plus $2 \mathrm{mg}$ DRSP for the treatment of climacteric symptoms ${ }^{21,23-25}$ This association has anti-androgenic and anti-aldosterone properties. 22,23

The present study was designed to assess the endometrial effects (bleeding patterns, endometrial thickness, hysteroscopic pattern, and endometrial histology) in postmenopausal women using lowdose estradiol associated with either LNG-IUS or oral drospirenone.

\section{Methods}

A study was carried out with women receiving care at the Menopause Clinic of the Hospital de Clinicas de Porto Alegre (registered in the Registros Brasileiros de Ensaios Clínicos - REBEC U11111133-7919). Patients were enrolled from November 2005 until September 2007. Women were included if they were postmenopausal (amenorrhea for at least 12 months or 6 months of amenorrhea and FSH $>40$ UI), if they had an intact uterus and menopause symptoms, if they were willing to take HT, if they were amenorrheic for less than 10 years and were younger than 65 years of age, if they had not used HT in the past six months and if they had a normal mammogram and Pap smear in the last 12 months. Patients with a history of any cancer, coronary disease, uncontrolled systemic hypertension, venous thrombosis, renal failure or hepatic failure were excluded. This project was initiated as a pilot study and the sample size was estimated using the variable vaginal bleeding. However, it was difficult to enroll patients and the study was discontinued when all patients had met the criteria and agreed to participate in the period from November 2005 to September 2007. Thirty-four patients met the inclusion criteria and were included in the study.

All participants signed an informed consent form. The study was approved by the Research Ethics Committee at Hospital de Clinicas de Porto Alegre (project 05-262).

After signing written terms of informed consent, patients underwent anamnesis and physical examination with height, weight and blood pressure measurements. The Kupperman index was also determined. Blood was collected to examine the lipid profile and glucose level.

All transvaginal ultrasound examinations (to measure endometrial thickness) were performed at the Obstetrics and Gynecology Department of Hospital de Clinicas de Porto Alegre by the same operator, with the same equipment (Aloka, SSD - 
1700), with a transvaginal, convex, electronic 5 MHZ probe. The patients then underwent a hysteroscopy and endometrial sampling (using a Pipelle device). Hysteroscopy was carried out as an outpatient procedure with a type II Hamoumicrocolpohysteroscope.

Eligible women were randomly assigned to one of two groups: LNG-IUS $(\mathrm{n}=17)$, receiving $1 \mathrm{mg}$ estradiol daily p.o. in association with LNG-IUS (releasing $20 \mu \mathrm{g} /$ day levonorgestrel); DRSP $(\mathrm{n}=17)$, receiving $1 \mathrm{mg}$ estradiol daily combined with drospirenone $2 \mathrm{mg}$ /day p.o. The LNG-IUS was inserted at the time of hysteroscopy. A bleeding diary was provided and explained to participants. In this diary, patients recorded episodes of vaginal bleeding and classified them as light/spotting, moderate or severe.

Patients returned after $1,3,6,9$, and 12 months (day one $=$ hysteroscopy day). On each of these occasions, the severity of symptoms was reassessed using the Kupperman index, and blood pressure was measured. The bleeding diary was checked. The glucose level and lipid profile were measured again after 6 and 12 months. Transvaginal ultrasound, Pap smear, hysteroscopy and the endometrial sampling during hysteroscopy were repeated at the end of 12 months of treatment.

The data for quantitative variables is shown as mean \pm SD. All categorical variables were described as percentages. Variables were tested for normal distribution and Student's $t$ test was used for independent samples and ANOVA for repeated measures when appropriate. All data were processed and analyzed using Excel 2000 and SPSS 14.0. Data were considered to be significant when $p<0.05$.

\section{Results}

Twenty-eight patients completed the 12 months of the study: 15 from the LNG-IUS/estradiol group and 13 from the DRSP/estradiol group. Early withdrawals from the study were related to: breast cancer diagnosed after 6 months of HT ( 1 from the LNGIUS group); moving to another city (3 from the DRSP group), and dropouts (who did not show up for follow-up appointments nor answer phone calls, 1 from each group).

In both study groups, the number of daily hot flushes decreased and there was symptomatic improvement in other aspects evaluated using the Kupperman Index.

The mean age of patients in the LNG-IUS/estradiol group was 52.53 (44-59) years vs. 53.15 (43-60) in the DRSP group. No differences in baseline demo- graphic characteristics were found between the two groups (Table 1). Vaginal bleeding was reported after one month of treatment by eight patients $(53.3 \%)$ in the LNG-IUS group. Of those, five classified the bleeding as light/spotting and three as moderate; in the DRSP group, only one patient $(7.7 \%)$ reported bleeding and classified it as spotting. There was a progressive (non-linear) reduction in reported bleeding over time. The time/treatment effect can be observed in terms of vaginal bleeding: 17 bleeding episodes in the first trimester of treatment, followed by 9 in second, none in the third and one episode in the last 3 months in the LNG-IUS group. The same can be observed for the DRSP group: 4 bleeding episodes in the first trimester, 4 in the second, 2 in the third and none in the last 3 months. After 12 months, all patients were amenorrheic (Figures 1 and 2).

Mean endometrial thickness for the baseline in the LNG-IUS group was $4.43 \mathrm{~mm}$ compared with $5.00 \mathrm{~mm}$ at the end of the study. In the DRSP group, the baseline and end-of-study endometrial thickness were $4.29 \mathrm{~mm}$ and $4.77 \mathrm{~mm}$, respectively. One patient from the LNG-IUS group underwent hysteroscopic resection of a polyp before treatment and one patient from the DRSP had a polyp removed after the $12^{\text {th }}$ months of treatment. There was no statistical difference between the two groups regarding endometrial thickness over time $(p=0.922)$. The behavior of endometrial thickness was also similar ( $p=0.263$ ) (Figure 3 ).

The hysteroscopic evaluations performed at the beginning of the study revealed an atrophic endometrium in all but one patient (who had an endometrial polyp resection). After 12 months, hysteroscopy showed persistent atrophic endometrium in all but one patient from the DRSP group. Only three of the 34 patients were given general anesthesia for the initial hysteroscopy due to cervical stenosis. By the end of the study, after a year of hormone therapy, there was no need for anesthesia.

At the baseline, endometrial samples were analyzed by pathologists and an atrophic endometrium was found in 16 of 17 patients in each group. After treatment, an atrophic endometrium was still the most frequent finding, but in eight patients (seven in the LNG-IUS and one in the DRSP group), the effects of progestogen therapy with stromal decidualization and inactive glands were diagnosed, as shown in Table 2. 
Table 1

Baseline characteristics of the patients.

\begin{tabular}{lccc}
\hline \multirow{2}{*}{ Characteristics } & LNG-IUS group & DRSP group & \multirow{2}{*}{$\boldsymbol{p}^{*}$} \\
\cline { 2 - 3 } & $\overline{\mathrm{X}} \pm \mathrm{SD}$ & \\
\hline Age (years) & $52.53 \pm 4.44$ & $\overline{\mathrm{X}} \pm \mathrm{SD}$ & \\
Time since menopause (months) & $51.60 \pm 43.14$ & $53.15 \pm 4.018$ & 0.703 \\
BMI & $27.35 \pm 3.92$ & $44.23 \pm 41.62$ & 0.651 \\
SBP (mm Hg) & $122.13 \pm 10.73$ & $28.98 \pm 3.98$ & 0.286 \\
DBP (mmHg) & $75.73 \pm 8.21$ & $830.46 \pm 21.87$ & 0.203 \\
Kupperman Index & $27.47 \pm 9.77$ & $28.38 \pm 6.92$ & 0.093 \\
Number of daily hot flushes & $6.80 \pm 4.16$ & $10.46 \pm 7.26$ & 0.780 \\
HDL-c (mg/dl) & $66.87 \pm 17.69$ & $59.08 \pm 10.52$ & 0.108 \\
Triglycerides (mg/dL) & $147.47 \pm 87.50$ & $138.38 \pm 68.81$ & 0.177 \\
Glucose (mg/dL) & $90.27 \pm 5.31$ & $87.92 \pm 6.16$ & 0.765 \\
Endometrial thickness (mm) & $4.43 \pm 1.86$ & $4.29 \pm 2.41$ & 0.289 \\
\hline
\end{tabular}

*Student's $\mathrm{t}$ test; $\mathrm{BMI}=$ body mass index; SBP= systolic blood pressure; $\mathrm{DBP}=$ diastolic blood pressure.

Figure 1

Vaginal bleeding in the LNG-IUS group over one year of treatment.

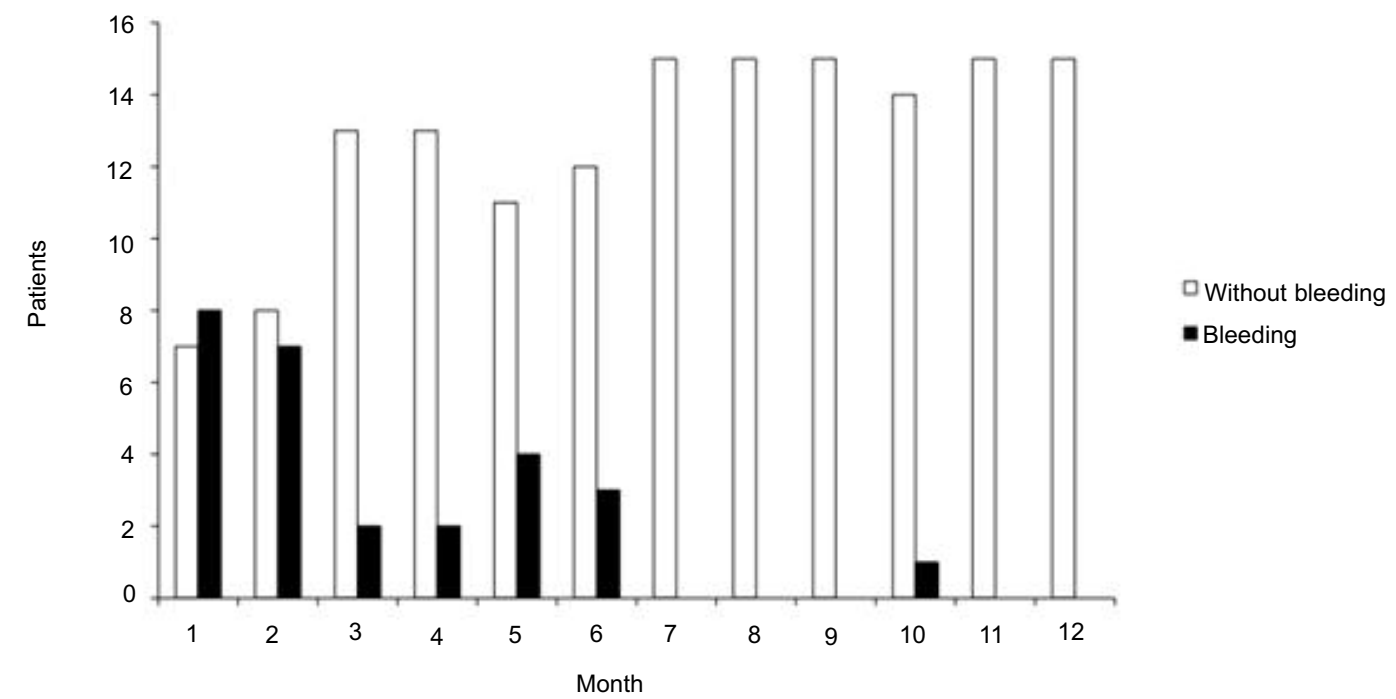

LNG-IUS = levonorgestrel releasing intrauterine system. 
Vaginal bleeding in the DRSP group over one year of treatment.

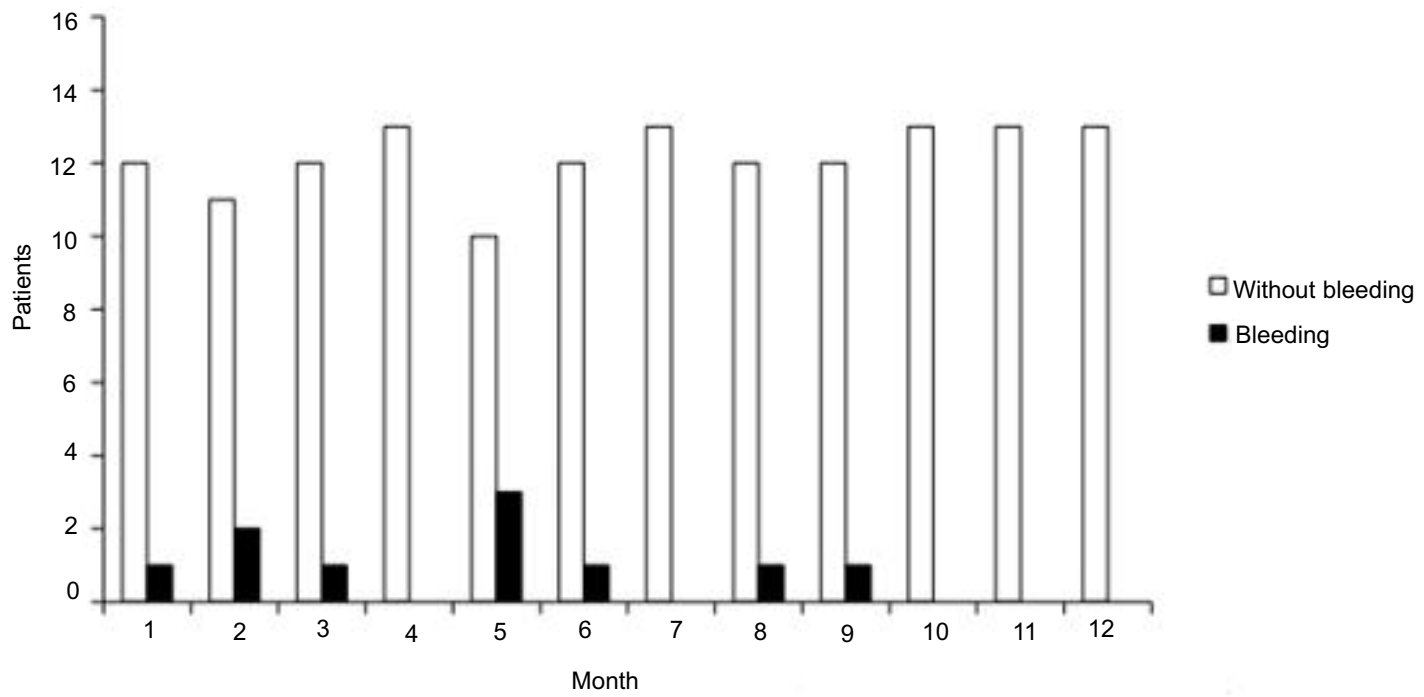

DRSP $=$ Drospirenone...

Figure 3

Endometrial thickness before and after one year of treatment in the LNG-IUS and DRSP groups.

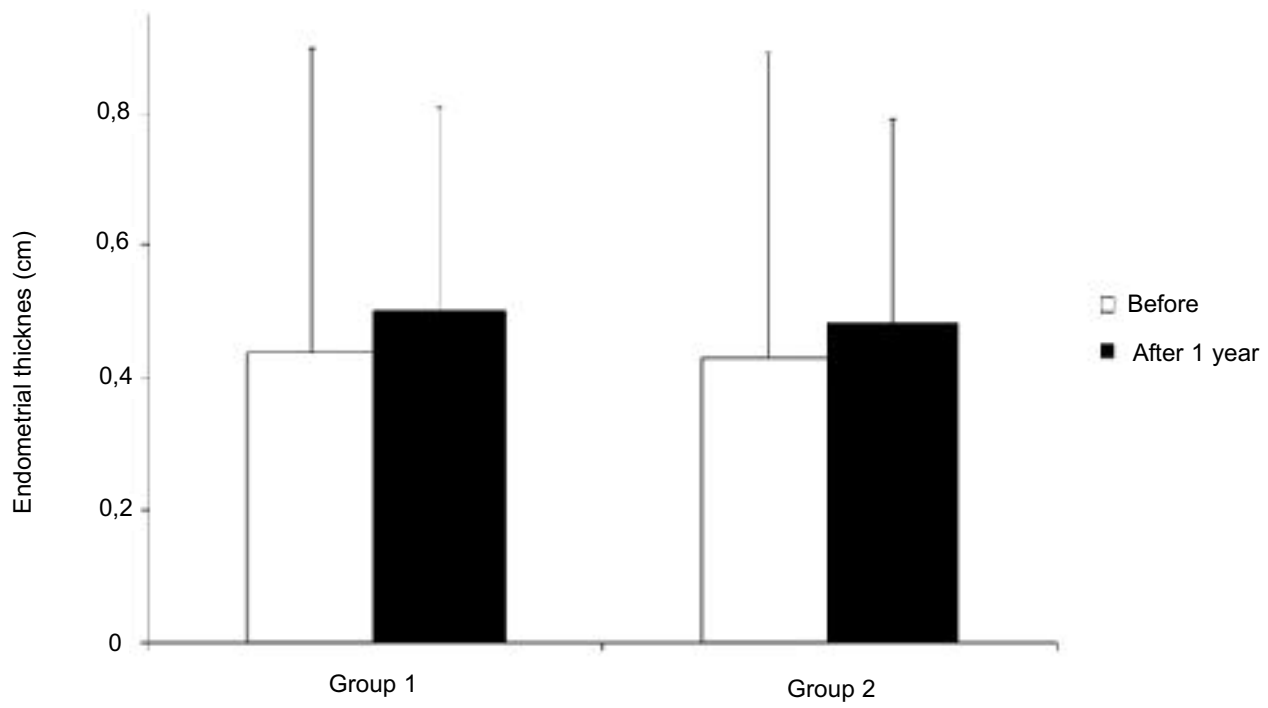

LNG-IUS = levonorgestrel releasing intrauterine system; DRSP = Drospirenone; ANOVA for repeated measures, not significant, $p>0.05$. 
Histological findings before and after one year of treatment in the LNG-IUS group (low dose estrogen + LNG-IUS) and DRSP group (low dose estrogen + drospirenone). *Stromal decidualization and inactive glands.

\begin{tabular}{lcccc}
\hline Endometrial histology & \multicolumn{2}{c}{ LNG-IUS group } & \multicolumn{2}{c}{ DRSP group } \\
\cline { 2 - 4 } & Before $(n=17)$ & After $(n=15)$ & Before $(n=17)$ & After $(n=13)$ \\
\hline 1. Atrophic & 16 & 8 & 16 & 10 \\
2. Proliferative & 0 & 0 & 1 & 0 \\
3. Polyp & 1 & 0 & 0 & 1 \\
4. Effects of progestogen therapy* & 0 & 7 & 0 & 2 \\
\hline
\end{tabular}

LNG-IUS = levonorgestrel releasing intrauterine system; DRSP = Drospirenone

\section{Discussion}

In this randomized one-year study of postmenopausal women, we observed a low bleeding rate, with a progressive decrease after both types of HT, as described in the literature.12,17 To the best of our knowledge, our study is the first to compare the endometrial effects of low dose estradiol $(1 \mathrm{mg} /$ day, p.o.) associated with LNG-IUS. Archer et al.24 reported similar results with estradiol/drospirenone combined therapy. High rates of amenorrhea have been described after one year of combined LNG-IUS in addition to the conventional estrogen dose.18-20 Raudaskoski et al. 19 found a greater incidence of bleeding/spotting in the first trimester with estradiol/LNG-IUS ( $86 \%$ of patients, compared with $11.8 \%$ of patients receiving oral combined therapy). After 12 months, only three patients (from the LNGIUS group) in that study presented any bleeding. After a one-year follow-up, Varila et al. 20 reported amenorrhea in $64 \%$ of patients using LNG-IUS associated with transdermal $50 \mu \mathrm{g} 17 \beta$ estradiol daily. Raudaskoski et al.18 in a one-year multicenter randomized trial, observed $90.9 \%$ of amenorrhea during the last 3 months in patients receiving LNGIUS in addition to estradiol valerate ( $2 \mathrm{mg}$ /day). In the present study, we observed a trend for vaginal bleeding to decrease over time with the use of $1 \mathrm{mg}$ estradiol plus LNG-SIU. A smaller number of patients had bleeding in the DRSP group. Even though patients using LNG-IUS in combination with estradiol valerate experienced more bleeding complaints, the frequency was not statistically different between the two groups. At 12 months, $100 \%$ amenorrhea had been achieved by both treatments.

Measurement of the thickness of the endometrium using transvaginal ultrasound, always performed by the same physician, provides an accu- rate evaluation. We did not find significant differences in endometrial thickness between groups after 12 months of HT, which corroborates the findings of previous studies. 18,19 These data were also correlated with hysteroscopy findings and endometrial histology results. An atrophic endometrium was the most frequent histological finding after treatment (64.3\% of patients in both groups). We found a difference in histological results after one year. Stromal decidualization and inactive glands as a result of progestogen therapy were found in $46.7 \%$ of the patients in the LNG-IUS group, compared with only $15 \%$ of the DRSP group. This reflects the strong effect of levonorgestrel released directly into the endometrium. A similar effect was described with the conventional estrogen doses associated with LNG-IUS. 19

This study has a number of limitations. Although we used randomized treatment allocation, it was not double-blind, because the patients had to be informed of insertion of the LNG-IUS. Another limitation was the small sample size, which may have precluded the detection of effects. Vaginal bleeding decreased over time both in patients treated with LNG-IUS plus estradiol and in thus treated with drospirenone plus estradiol. All patients were amenorrheic after one year. Our results suggest good endometrial protection for postmenopausal women with both regimens, with no difference between treatments after one year.

\section{Acknowledgements}

This study received financial support from the Fundo de Incentivo a Pesquisa (FIPE) do Grupo de Pesquisa e Pós-Graduação (GPPG) of the Hospital de Clinicas de Porto Alegre. Edison Capp receives a grant from the $\mathrm{CNPq}$. 


\section{References}

1. National Institutes of Health State-of-the-Science Conference Statement: Management of Menopause Related Symptoms Ann Intern Med, Jun 2005; 142: 1003 - 1013. Ann Intern Med. 2005; 142: 1003-13.

2. Estrogen and progestogen use in postmenopausal women: July 2008 position statement of The North American Menopause Society. Menopause. 2008; 15: 584-602.

3. Hickey M, Davis SR, Sturdee DW. Treatment of menopausal symptoms: what shall we do now? Lancet. 2005; 366 (9483): 409-21

4. Management of osteoporosis in postmenopausal women: 2006 position statement of The North American Menopause Society Menopause. 2006; 13: 340-67.

5. Writing Group for the Women's Health Initiative Investigators. Risks and benefits of estrogen plus progestin in healthy postmenopausal women: principal results from the Women's Health Initiative randomized controlled trial. JAMA. 2002; 288: 321-33.

6. Chlebowski RT, Hendrix SL, Langer RD, Stefanick ML, Gass M, Lane D, Rodabough RJ, Gilligan MA, Cyr MG Thomson CA, Khandekar J, Petrovitch H, McTiernan A; WHI Investigators. Influence of estrogen plus progestin on breast cancer and mammography in healthy postmenopausal women: the Women's Health Initiative Randomized Trial. JAMA. 2003; 289 (24): 3243-53.

7. Rossouw JE, Anderson GL, Prentice RL, LaCroix AZ, Kooperberg C, Stefanick ML, Jackson RD, Beresford SA, Howard BV, Johnson KC, Kotchen JM, Ockene J; Writing Group for the Women's Health Initiative Investigators. Risks and benefits of estrogen plus progestin in healthy postmenopausal women: principal results From the Women's Health Initiative randomized controlled trial. JAMA. 2002; 288(3): 321-33.

8. Beral V. Breast cancer and hormone-replacement therapy in the Million Women Study. Lancet. 2003; 362 (9382) 419-27.

9. Guidelines for the hormone treatment of women in the menopausal transition and beyond - Position statement by the Executive Committee of the International Menopause Society. Maturitas. 2004; 48: 27-31

10. Climateric medicine: European Menopause and Andropause Society (EMAS) statements on postmenopausal hormonal therapy. Maturitas. 2004; 48: 19-25.

11. Gompel A, Barlow D, Rozenberg S, Skouby SO. The EMAS 2006/2007 update on clinical recommendations on postmenopausal hormone therapy. Maturitas. 2007; 56 (2) 227-9.

12. Archer DF. Endometrial bleeding during hormone therapy: the effect of progestogens. Maturitas. 2007; 57 (1): 71-6.

13. Weiderpass E, Adami HO, Baron JA, Magnusson C, Bergstrom R, Lindgren A, Correia N, Persson I. Risk of endometrial cancer following estrogen replacement with and without progestins. J Natl Cancer Inst. 1999; 91 (13): 1131-7
14. Anderson GL, Limacher M, Assaf AR, Bassford T, Beresford SA, Black H, Bonds D, Brunner R, Brzyski R, Caan B, Chlebowski R, Curb D, Gass M, Hays J, Heiss G, Hendrix S, Howard BV, Hsia J, Hubbell A, Jackson R, Johnson KC, Judd H, Kotchen JM, Kuller L, LaCroix AZ, Lane D, Langer RD, Lasser N, Lewis CE, Manson J, Margolis K, Ockene J, O'Sullivan MJ, Phillips L, Prentice RL, Ritenbaugh C, Robbins J, Rossouw JE, Sarto G, Stefanick ML, Van Horn L, Wactawski-Wende J, Wallace $\mathrm{R}$, Wassertheil-Smoller S; Women's Health Initiative Steering Committee. Effects of conjugated equine estrogen in postmenopausal women with hysterectomy: the Women's Health Initiative randomized controlled trial. JAMA. 2004; 291 (14): 1701-12.

15. Nelson HD. Commonly used types of postmenopausal estrogen for treatment of hot flashes: scientific review. JAMA. 2004; 291 (13): 1610-20.

16. Smith NL, Heckbert SR, Lemaitre RN, Reiner AP, Lumley T, Weiss NS, Weiss NS, Larson EB, Rosendaal FR, Psaty $\mathrm{BM}$. Esterified estrogens and conjugated equine estrogens and the risk of venous thrombosis. JAMA. 2004; 292 (13): 1581-7.

17. Varma R, Sinha D, Gupta JK. Non-contraceptive uses of levonorgestrel-releasing hormone system (LNG-IUS)--a systematic enquiry and overview. Eur J Obstet Gynecol Reprod Biol. 2006; 125 (1): 9-28.

18. Raudaskoski T, Tapanainen J, Tomas E, Luotola $\mathrm{H}$, Pekonen F, Ronni-Sivula H, Timonen H, Riphagen F, Laatikainen $\mathrm{T}$. Intrauterine $10 \mathrm{microg}$ and 20 microg levonorgestrel systems in postmenopausal women receiving oral oestrogen replacement therapy: clinical, endometrial and metabolic response. BJOG. 2002; 109 (2): 136-44.

19. Raudaskoski TH, Lahti EI, Kauppila AJ, Apaja-Sarkkinen MA, Laatikainen TJ. Transdermal estrogen with a levonorgestrel-releasing intrauterine device for climacteric complaints: clinical and endometrial responses. Am J Obstet Gynecol. 1995; 172: 114-9.

20. Varila E, Wahlstrom T, Rauramo I. A 5-year follow-up study on the use of a levonorgestrel intrauterine system in women receiving hormone replacement therapy. Fertil Steril. 2001; 76 (5): 969-73.

21. Fuhrmann U, Krattenmacher R, Slater EP, Fritzemeier KH. The novel progestin drospirenone and its natural counterpart progesterone: biochemical profile and antiandrogenic potential. Contraception. 1996; 54 (4): 243-51.

22. Krattenmacher R. Drospirenone: pharmacology and pharmacokinetics of a unique progestogen. Contraception. 2000; 62 (1): 29-38.

23. Palacios S, Foidart JM, Genazzani AR. Advances in hormone replacement therapy with drospirenone, a unique progestogen with aldosterone receptor antagonism. Maturitas. 2006; 55 (4): 297-307.

24. Archer DF, Thorneycroft IH, Foegh M, Hanes V, Glant MD, Bitterman P, Kempson RL. Long-term safety of drospirenone-estradiol for hormone therapy: a randomized, double-blind, multicenter trial. Menopause. 2005; 12 (6): 716-27. 
25. Schurmann R, Holler T, Benda N. Estradiol and drospirenone for climacteric symptoms in postmenopausal women: a double-blind, randomized, placebo-controlled study of the safety and efficacy of three dose regimens. Climacteric. 2004; 7 (2): 189-96.

Recebido em 18 de outubro de 2012

Versão final apresentada em 29 de abril de 2013

Aprovado em 25 de junho de 2013 